\title{
The Problem Related With Community Radio Concept and Restarting of Community Radio in Sri Lanka
}

\author{
R. Saman Rajapaksha, A.G. Amali Uthpala Nandasiri \\ University of Kelaniya, Kelaniya, Sri Lanka
}

\begin{abstract}
Community radio can be considered as an appropriate media of developing the knowledge and attitudes of listeners by clearly identifying their ideas. Community radio services aid to motivate the community participation in communication successfully, as well as to strength the cultural rights of community. It is a current necessity to use community radio services in the process of obtaining successful results through the currently activated developing projects in Sri Lanka. Many countries in the world use this system to succeed their development projects. In this background, there is a necessity to explore the developmental competencies of community radio in Sri Lanka. Community interests for restarting the community radio in Kothmale, Mahaelluppallama and Giradurukotte were identified by the field research. This research proposes a noval format to restarting and continuous implementation of community radio in Sri Lanka, with the factors revealed in the survey. This project is activated under several steps as a collaborative project of Sri Lanka Broadcasting Corporation (SLBC), the Department of Mass Communication, University of Kelaniya and the community. Proposed community radio will be controlled by a co-administrative system of University of Kelaniya and community. Technical support and frequency will be taken from Sri Lanka Broadcasting Corperation. The content of programs for community radio will be selected by University of Kelaniya and the community. Financial support will be given by the University of Kalaniya for a period of one year. After that, community radio should get the responsibility for its sustainability. Funds will be obtained through various departmental projects, public services, state and non-governmental organization. Those organizations don't have a media to implement programs which focuses on rural development. This new radio format could be used for that purpose. This model named as Campus Community Radio (CCR). It is important to discuss the restarting of community radio services in Sri Lanka, based on the facts such as the incapability of supplying the necessities of listeners in a background of hypermedia. In addition, failure of identifying the developmental expectations of listeners for the radio services in a national level and the usage of community radio services by many countries in the world such as Philippines and India for the success of their rural projects.
\end{abstract}

Keywords: community radio, restarting, community, campus community radio, development

\section{Introduction}

Sri Lankan radio industry can be categorized under four layers. They are national radio, regional radio, community radio, and web radio. According to the ownership pattern, national radio can be divided into two parts. They are government and private radio stations (Fraser \& Estrada, 2001). All the regional and community

R. Saman Rajapaksha, B.A., M.Phil., Senior Lecturer, Department of Mass Communication, University of Kelaniya.

A.G. Amali Uthpala Nandasiri, B.A., M.Phil., Sub-editor of NOK e-newspaper, Department of Mass Communication, University of Kelaniya. 
radio services are owned and managed by the government radio arm, Sri Lanka Broadcasting Corporation (SLBC).

Community radio and its present condition is the background of this study. As a result of acerbated Mahaveli development project, which is the largest development project in Sri Lanka since independence. Sri Lankan community radio was established to achieve development goals and to minimize the communication gap among the Mahaveli settlers. Accordingly, Mahaveli community radio was established in 1981, with the support of UNESCO and, DANEEDA project of Denmark with the collaboration of Sri Lanka Broadcasting Corporation (SLBC).

After starting the Mahaveli community radio (1981), Mahaelluppalama (1981) and GiraduruKotte (1986) Community Radios were started respectively. Community radio was failed for many reasons at the end of 1990's. Kothmale was a different model for community radio with its internet radio facility. Uva was established under the different aims and objectives.

At present Uva community radio is the only radio channel which is functioning in the framework of community radio. In addition, Giradurukotte was renamed as "Dambana fm" functioning as a different kind of Community station for indigenous Vadda community of Sri Lanka.

The reasons for the breakdown of the Mahawali community radio were studied by many researchers and projects. UNESCO evaluation reports, Victor T. Valbuena's studies, Tilak Jayarathna and Dr. Kalinga Senevirathna's studies are few of them (Final Evaluation of the Mahaweli Community radio project: 1990) (Valbuena, 1988).

At present, Sri Lankan national broadcasting media has expanded. There, forty-three (43) radio channels are functioned under the ownerships of government and private. But it is revealed that the national radio channels have failed to fulfill the needs of the listeners in the entire country. Moreover, specific groups, which are based on the economic and social modernization, those who are engaged in different occupations and functions, can be identified in the modern social context in Sri Lanka. Therefore, the need of a community radio is felt once again. Accordingly, it is expected to re-establish the community radio, whichhile it is not presently implementing in Sri Lanka. As the first step, there is a proposal for implementing campus community radio, with the support of the higher education institutions such as universities.

This study was based on two listener surveys to understand the level of aspiration of public regarding the restarting and continuous implementation of community radio in Sri Lanka (Listener survey in Kothmale, 2008; Nandasiri, 2012). These listener surveys were done in areas of Kothmale and Mahaelluppallama. Accordingly, one can have positive hopes about the restarting of Sri Lankan Community Radio, through the unrevealed data. (Nandasiri, 2012). The problems revealed by the above research were of great help to introduce the new community radio model. There, not elaborate those problems caused for the failure of community radio model of the country. But we identify new trends of broadcasting in Sri Lanka. In this study proposed a new model of implementation of community radio in Sri Lanka.

\section{The CCR (Campus Community Radio) Model}

\section{What is CCR?}

CCR is not a internal suggestion which came from the academia. According to the survey, it was also suggested by the community concerned. Community radio was started in Sri Lanka with the objective of fulfilling the need of policy makers. The need for community radio did not come from the community 
concerned. As Tilak Jayarathne correctly pointed out, the idea of community radio is not based on assessment of needs of the community.

A new community radio model named as CCR. CCR is "Campus Community Radio". There are many discussions had been held on Community Radio in several academic forums, since 2005. National Media Summit 2010, which was held in the University of Kelaniya, with the participation of almost all the communication and media academics of the country-agreed to apply for the community radio license from the government for all the universities. Apart from that Sripalee campus-Horana (University of Colombo) started campus community radio by using the temporary frequency given by the Sri Lanka Broadcasting Corporation. But it was unsuccessful within a short period. CCR means Community radio broadcasting conducted by the campus community for their respective community.

\section{Vision of CCR}

How does the campus community contribute to social development? There is an effective method in CCR. Vision of CCR is "Contributing to uplift the community by strengthening them physically and mentally, with the help of the development projects that has national value, by injecting new knowledge and thinking which originates in the university".

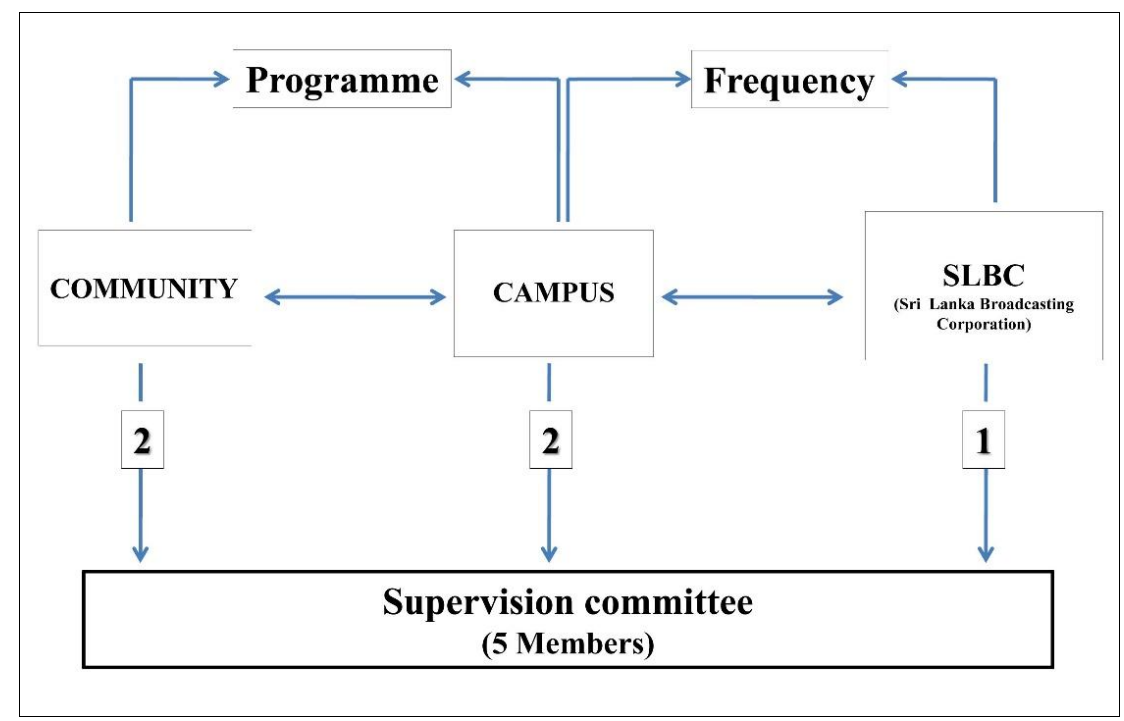

Figure 1. CCR Model.

This present model (see Figure 1) is based on Sri Lankan universities but with two other institutions. They are the university community and the Sri Lanka Broadcating Corporation (SLBC) recent surveys show that, the need for community radio in community is increasing. Those studies are revealed that in present, national radio channels don't fulfill the needs of community at large.

But studies reveal that the people like to work with a community radio, which cater their needs. They like to share their socio-economic problems with community-based forums. In this model, we have chosen Sri Lanka Broadcating Corporation (SLBC) to obtain frequency. According to the latest reallocation of frequency, there is one frequency for community radio. But, we can't get this frequency without SLBC. Because, there is no sufficient law that get to Frequency other than the Sri Lanka Broadcating Corporation (SLBC). One clear example is the "Gami Diriya - Saru Radio" in Polonnaruwa. Although all the infrastructure and facilities are 
there, the radio cannot be started without a frequency. Therefore, the Sri Lanka Broadcating Corporation (SLBC) will join only as a partner of frequency.

\section{The Functioning Method of CCR}

This project implements under the supervision of the university, community and SLBC. Task implementing and broadcasting of CCR is done by the approval and supervision of a committee. Supervision committee is consisting of the members of university, community and Sri Lanka Broadcating Corporation (SLBC).

The composition of the Supervision committee is as follows:

(1) One representative from Sri Lanka Broadcating Corporation (SLBC).

(2) Two members representing University, Coordinator and Producer/Announcer.

(3) Two members representing the community.

Community representative will be selecting among the public. One person will be selected from the agricultural organizations of the region. The members of agricultural organization will be given opportunity to name their representative. The other will be selected from development committees of the area. An opportunity will be given to the members to name him.

\section{The Operation of CCR}

In implementing CCR in university of Kelaniya, the Sri Lanka Brodcasting Corporation and the department of Mass communication should understand their responsibilities separately.

- University

(1) will make the formats and the content of programs.

(2) has the sole responsibility of the programs broadcaste in community radio.

(3) providing announcers, script writers, producers, technicians and field officers.

(4) appointing member for the supervision committee to continue tasks of community radio.

(5) providing financial support one year from its start.

- Community

(1) contribute to produce and nourishment of content of programs.

(2) appointing a member to the committee to continue the tasks of community radio.

(3) organizing and leading the community.

(4) creating a good bond between community radio and the community.

- Sri Lanka Broadcating Corporation (SLBC)

(1) to providing technical support.

\section{Service of CCR}

(1) Building a format that relates university radio station, community radio and community, to make the community to participate for the development.

(2) Broadcasting radio programs that focus attention on community development projects in the country.

(3) Broadcasting radio programs that is inter-connected with the entire life and its cultural identities of the community.

(4) Identifying the requirements of community when producing programs.

(5) Proceeding new community redio as a research centre for social development.

(6) Establishing new community radio as a research centre for undergraduates, post graduates and all the students. 


\section{Financial Sources' Producing and Sustainable}

At the beginning, there will be a co-contribution of Sri Lanka Broadcastion Corporation and university of kelaniya in doing tasks of community radio. Thus, for the transmission and airtime provided by radio station, find instruments, studio organizing, repairing and other maintenance and paying water and electricity bills in the community radio premises should be done by the university.

(1) The university will be paying money or the airtime given by the Sri Lanka Broadcasting Corporatin after one year from starting CCR (with the agreement of both parties).

(2) The tasks mentioned in the first step will be changed with the agreement of both parties after paying money for air time.

(3) Providing financial support for the projects will be done by government, non-governmental and volunteer organizations.

(4) Earn money for selling airtime.

\section{Ethics, Activity and Guidelines of CCR}

Since Sri Lankan universities are situated in urban, suburb and rural areas, a radio can be started in university premises as a first step. Further, university can go to rural areas too. At present thirteen universities plan to use this model to uplift the suitable and practical social conditions in Sri Lanka. These factors are still in the negotiating stage. It should be emphasized that CCR format in university takes the prominence. CCR is a new experiment, a new beginning. Our aim is to re-establish a suitable concept of community radio in Sri Lanka.

\section{Conclusions}

Community is a set of people who live in a particular geographical land for a same objective. There is a similarity in their objectives, attitudes and behavior. Therefore, community radio is established in order to make the community to participate in the process of community development and achieve sustainable development.

But could community radio be used to community participation in this way? Could the community be persuaded to achieve community development? All these have in depth when analyzing properly these fundamental questions in applying this experimentation. Even though there's no definition about the concept of community; it is a new trend for the members of the community to be modernized. In such a background, the function and the requirement of the community tend to change. Social opportunities related to community have also faced a massive change. The management structures of community have modernized as well. Some mixed features could also be identified in the culture of the community.

The community has modernized physically as well as spiritually. The occupations, which were based on collective human labour, is now being controlled by machines. All the earning methods, which had a rhythmic improvement, have now, being changed in the face of marketing economy. Accordingly, the labour and the economy of the community has influenced by the industrialization. The life of the villagers that was mingled with the paddy field, threshing ground, village boutique etc. have modernized now, with a huge transformation. Therefore, supermarkets, which fulfill all the requirements of the community, are being established.

The nature of the relationship of the religious place, which was the centre for spiritual development, and the community, is also being modernized. The folk culture with folk drama, art and rituals are transforming and need could be identified that the established knowledge modes, which was based on political and economic advertising is attending to fulfill all the requirements of rural community. 
As mentioned above, all the radio listener surveys conducted recently revealed that a wise party is needed for the advertising purpose of the community. A set of State, non-governmental and volunteer organizations and officers could be identified from the society. But every organization does an isolated service to the society. In such a situation, most of the organizations and officers of rural areas are passive. Therefore, there is a weakness in implementing the decisions taken by the policy makers. In this situation, the community is unaware of some policies and their rights and responsibilities. Therefore, in order to develop all these relationship, a mediator is needed with the help of the community as well. After starting the CCR, an active involvement will be received to strengthen and develop the community.

Accordingly, CCR should fulfill the requirements of community, take steps for the community to participate in development process and it can organize the community. For that, all the community organizations and services should work together. So, in starting CCR, the contribution of the projects, companies, organizations and professionals of the community development mentioned below will be obtained. Moreover, CCR will get the coordinating ability of all these social services and organizations.

The participation and awareness of community in order to make the events that focus on development, economic and social development projects done by provincial and regional councils, divisional secretariats, various social services projects, community police project, development programmes of national youth Council, through CCR.

Those who do services for the community such as "Grama niladari", "Samurdi" development officeres, Agricultural research and development officer, PHI etc. When starting CCR, the things related to community such as new cultural, political and economical factors should be analyzed according to the above mentioned view. Moreover, the true necessity of the community should be identified. It should be decided as to how the Radio could be involved. For that, the influence could be taken from the functions and responsibilities of Community radio now operating in Sri Lanka. Further, the modern radio contents and social and cultural tradition related to radio should be studied.

\section{References}

Encyclopeidia of Social Movement Media. (2011). John D.H. Dowing (Edit). Retrieved from https://books.google.lk/books?isbn=0761926887

Final Evaluation of the Mahaweli Community radio project. (1990). UNESCO.

Fraser, C., \& Estrada, S. R. (2001). Community Radio Hanbook. UNESCO.

Listener Survey in Kothmale. (2008). Communication researches unite. Department of Mass Communication, University of Kelaniya, Sri Lanka.

Nandasiri, A. U. (2012). Radio and the taste of listerners (Specifically Mahailluppallama, Senapura \& Aluwiharegama in Anuradhapura Distric). Department of Mass Communication, University of Kelaniya, Sri Lanka.

Slater, D., Techch, J., \& Lewis, P. (2002). Ethographic monitoring and evaluation of community multimedia centre: A study of Kothmale Commnity Radio Internet Project. Sri Lanka, London.

The Sage handbook of action research. (2015). Hilary Brabury (Edit.). London.

Valbuena, T. V. (1988). Mahaweli community radio project: An evaluation. Asian Mass Communication Research and Information Centre, Singapore. 